\title{
Nominal contracts and the payment system
}

\author{
Hajime Tomura ${ }^{1}$
}

Received: 9 May 2020 / Revised: 11 July 2020 / Accepted: 11 July 2020 / Published online: 25 July 2020

(C) The Author(s) 2020

\begin{abstract}
This paper introduces into an overlapping generations model the civil court's inability to distinguish different qualities of goods of the same kind. This friction prevents the enforcement of real credit contracts through the civil court. Given this environment, fiat money is introduced into the model as an intrinsically useless, but recognizable instrument for the court. With fiat money, there exists an equilibrium in which agents write pledgeable nominal debt contracts, while fiat money circulates as both a means of debt repayment and a means of payment for goods. This result does not require dynamic inefficiency or lack of double coincidence of wants. However, there can occur a shortage of real money balances for debt repayments, because lenders must pay fiat money for borrowers' output before receiving the repayment of debt, in order for borrowers to obtain fiat money to repay debt. The central bank can resolve this bottleneck if it provides an elastic money supply through a discount window within each period. These results replicate two institutional features of the current monetary system - that is, fiat money being legal tender and a discount window offered by the central bank-in an unified framework.
\end{abstract}

Keywords Nominal contract · Discount window · Trade credit · Payment system · Legal tender

JEL Classification · E42 · E51 · E58

\section{Introduction}

Credit contracts are usually nominal. This is true even for trade credit, in which producers buy inputs from suppliers on credit, and pay money to suppliers at a later date. This use of money is different from the standard theory on the need for money, in which buyers have to pay money to sellers because they cannot be

Hajime Tomura

htomura@waseda.jp

1 Faculty of Political Science and Economics, Waseda University, 1-6-1 Nishiwaseda,

Shinjyuku-ku, Tokyo 169-8050, Japan 
committed to repaying debt. See Samuelson (1958), Townsend (1980), Kiyotaki and Wright (1989), and Lagos and Wright (2005) for examples of seminal papers in the literature.

A possible explanation for this observation is that sellers require buyers to repay money even if buyers can be committed to repaying debt, because sellers need to buy goods from third parties due to lack of double coincidence of wants between buyers and sellers. Freeman (1996a) presents such a model to generate nominal debt endogenously. This explanation, however, must assume that sellers cannot pay buyers' products or IOUs to buy goods from third parties.

This paper presents an alternative friction that leads to the use of nominal debt contracts as well as the use of fiat money as a means of payment for goods. This result is not based on lack of double coincidence of wants between buyers and sellers. This paper shows that money is necessary even without this friction, because it is essential for credit.

More specifically, this paper introduces into an overlapping generations model the civil court's inability to distinguish different qualities of goods of the same kind. The underlying assumption is that, unlike quantities, the evaluation of qualities is inevitably subjective, and thus difficult to define objectively enough to be verifiable at the civil court. As a result, the civil court cannot regard it as a breach of contract if producers acquire inputs from suppliers by promising to deliver high-quality goods later, but then deliver low-quality goods instead to save the production cost. Ex ante, the expectation of this moral hazard problem discourages suppliers from entering into a real credit contract to provide trade credit to producers. Otherwise, the model is a standard overlapping generations model with dynamic efficiency, in which money is not essential. ${ }^{1}$

In contrast to goods, fiat money is assumed to be intrinsically useless, but recognizable by the civil court. This assumption reflects the fact that the nominal value of fiat money is just a number, which is easy to recognize. It is also consistent with the fact that even though law in each country usually allows the use of any lawful goods for a medium of exchange, it often designates fiat money issued by the central bank as legal tender in the country. ${ }^{2}$ The definition of legal tender is such that "a debtor cannot successfully be sued for non-payment if he pays into court in legal

\footnotetext{
1 To clarify, if there is any reader wondering why some government regulation, such as consumer protection, does not criminalize the production of low-quality goods, it is legal to trade low-quality goods at any agreed price in the model. This feature of the model corresponds to the freedom of contract in the civil code, which is a basic legal principle in practice. Thus, if a supplier disputes a real credit contract with a producer and files a civil case, then the civil court interprets the content of the contract, and makes a decision on whether to uphold the supplier's claim or not. Even if the civil court judges that low-quality goods fall into the type of good that the producer and the supplier has agreed to trade, there is no punishment by the government for trading low-quality goods, given the freedom of contract. On this point, note that it is legal to trade garbage in reality. It is beyond the scope of the paper why such trade is not prohibited by the government.

${ }^{2}$ For the U.S. case, see Section 31 U.S.C. 5103. This statute provides legal tender status for U.S. coins and currency, including Federal reserve notes. There is no federal statute mandating that a person or a private entity must accept U.S. coins and currency as payment for goods or services. For more explanation, see https://www.federalreserve.gov/faqs/currency_12772.htm (Accessed 5 October 2019).
} 
tender," given debt being denominated in the units of legal tender. ${ }^{3}$ Thus, in legal terms, fiat money is characterized as a debt-repayment instrument recognizable by the civil court in practice. This characterization of fiat money can be extended to commodity money such as gold, as stamping metal can produce a coin with a nominal value, regardless of the coin's metal content. Indeed, minted coins are usually designated as legal tender along with legal-tender notes issued by the central bank in each country.

Given the existence of a competitive goods market, the model shows that suppliers can provide trade credit to producers if producers are liable to repay fiat money. On one hand, suppliers do not have to pay fiat money for producers' products in the goods market, if producers deliver low-quality goods to the market to acquire fiat money. On the other hand, if producers fail to repay fiat money, then the civil court can seize their belongings, as the repayment of fiat money, or lack thereof, is verifiable. In this case, the court can sell the seized belongings for fiat money in the competitive goods market without determining the quality of each belonging it sells, because buyers in the market can distinguish the different qualities of goods, and exploit any arbitrage opportunity unless the pricing of each good is fair in the market. This feature of the model is consistent with the fact that the civil court normally sells foreclosed properties for cash through auctions in practice. It also implies that producers do not gain anything by delivering low-quality goods to the goods market or defaulting on nominal debt contracts. Thus, producers can be committed to selling high-quality goods to suppliers in the goods market, and then repaying their nominal debt by the fiat money acquired in the market.

This result is related to the literature on incomplete contracts and collateral, such as Hart and Moore (1994, (1998) and Kiyotaki and Moore (1997). While these papers analyze the private enforcement of a credit contract without the power of the civil court, this paper highlights the role of fiat money as a remedy to the limited ability of the civil court to make a credit contract enforceable without collateral. This result is also related to the literature on the optimality of nominal contracts for risk sharing, such as Jovanovic and Ueda (1997), Tabellini and Freeman (1998), and Doepke and Schneider (2017). These papers analyze the role of money as a unit of account, without characterizing money as a means of payment. In contrast, this paper focuses on an alternative friction that leads to the use of nominal debt contracts as well as the use of fiat money as a means of payment for goods.

Furthermore, this paper shows that suppliers must pay fiat money for goods sold by producers before receiving the repayments of debt in a monetary equilibrium in the model, because otherwise producers would not be able to obtain fiat money to repay debt. This bottleneck in the flow of fiat money can cause a shortage of real money balances for debt repayments, resulting in underproduction by producers. This problem can be resolved if the central bank can lend fiat money to suppliers elastically through a discount window at a zero interest rate within each period. This result is consistent with the existence of a standard liquidity facility offered by the

\footnotetext{
3 This definition is provided by the U.K. Royal Mint. See https://www.royalmint.com/help/trm-faqs/legal -tender-amounts/ (Accessed 6 April 2019).
} 
central bank in practice, such as intraday overdrafts of bank reserves for commercial banks. Thus, characterizing fiat money as a debt-repayment instrument recognizable by the civil court can explain both the circulation of fiat money in the economy and the need for a standard central-bank policy in practice.

This result adds to the literature that analyzes the need for an elastic money supply in the payment system, such as Freeman (1996a, (1996b, (1999), Zhou (2000), Smith (2002), Fujiki (2003, (2006), Martin (2004), Mills (2006), Antinolfi and Keister (2006), Gu et al. (2011), and Chapman and Martin (2013). This paper contributes to this literature by showing that a bottleneck in the flow of fiat money that leads to the need for an elastic money supply can be derived from a much simpler environment than complex traveling constraints in a spatial economy utilized in the literature. This paper is also related to the paper by Sargent and Wallace (1982), which shows that the central bank's discount window can nullify the negative effect of legal restriction that prohibits financial intermediaries from issuing small-denomination notes backed by private loans.

Other related papers are the works by Hancock and Wilcox (1996) and Afonso and Shin (2011), which analyze the demand and effect of intraday overdrafts in the interbank payment system using U.S. Fedwire data. ${ }^{4}$ This paper adds to these papers by deriving an endogenous need for intraday overdrafts offered by the central bank.

In addition, to highlight the limited ability of the civil court, this paper abstracts from asymmetric information among private agents. In related literature, Williamson and Wright (1994) show that introducing universally identifiable fiat money can improve welfare in an exchange economy, if traders can identify the quality of each other's commodity in bilateral trades only with some probability. ${ }^{5}$ Even though this paper also features universally identifiable fiat money, the focus is on the limited ability of the civil court, rather than asymmetric information among private agents. This approach yields a new finding that the need for two institutional features of the current monetary system - that is, fiat money being legal tender and a discount window offered by the central bank-can stem from the same friction. In addition, Kiyotaki and Moore (2005) characterize fiat money as a liquid substitute for illiquid private securities due to asymmetric information among private agents. Their model does not involve nominal contracts.

To clarify, there are many examples in history that commodities and securities of heterogeneous qualities circulated as monies with different purchasing powers simultaneously without having government stamps or legal tender status. ${ }^{6}$ Thus, the need for a debt-repayment instrument recognizable by the civil court does not explain all the needs for money in history. Nonetheless, it is useful to enhance the set of frictions

\footnotetext{
${ }^{4}$ More specifically, Hancock and Wilcox (1996) estimate the demand function for intraday overdrafts of bank reserves. Afonso and Shin (2011) simulate a calibrated network model of interbank payments, in which each bank delays payments to other banks if its intraday overdraft exceeds a certain threshold.

5 This is because universally identifiable fiat money is always accepted by the counterparty, and thus facilitates trade, whereas a commodity can be rejected by the counterparty with some probability if the counterparty cannot identify its quality.

${ }^{6}$ For example, see Gorton (1999) for private bank notes during the free banking era in the U.S in the 19 th century.
} 
that can explain the circulation of fiat money, because a different friction has a different implication for the future of the monetary system. For example, if the current need for fiat money stems from lack of credit or double coincidence of wants, or asymmetric information among private agents, then a private money, such as a cryptocurrency, may be able to substitute legal currencies, because the existence of a monetary equilibrium is spontaneous. If the underlying friction for the current use of fiat money is the need for a debt-repayment instrument recognizable by the civil court, however, a private money will not substitute legal currencies automatically, because legal tender is set by law in each country. In this case, a private money's success will hinge on whether it can substitute the role of the civil court in contract enforcement. This prediction is a testable implication of this paper's analysis.

The remainder of this paper is organized as follows. A baseline model without fiat money is described in Sect. 2. Fiat money and the central bank's discount window are introduced in Sects 3 and 4, respectively. Section 5 concludes this paper.

\section{Baseline model}

Time is discrete and indexed by $0,1,2, \ldots$ in order. A continuum of agents are born at the beginning of each period and live for two periods. The set of agents born in period $t$ is referred to as "cohort $t$ " for $t=0,1,2, \ldots$ Call agents in their first period "young", and those in the second period "old". The measure of agents on a continuum is defined by the Lebesgue measure.

In each cohort, there are two types of agents, producers and suppliers, each of which have a unit measure. Each supplier maximizes the following life-time utility function:

$$
U_{S, t}=\rho c_{S, Y, t}+c_{S, O, t+1},
$$

where the subscript $S$ indicates variables for a representative supplier; $t$ denotes the cohort of the supplier; $U_{S, t}$ denotes the life-time utility for the supplier; $c_{S, Y, t}$ and $c_{S, O, t+1}$ denote the supplier's consumption of goods when young and when old, respectively; and $\rho(\geq 0)$ is a utility weight. Each producer maximizes the consumption of goods when old. Agents have perfect foresight, given no shock in the model.

Each supplier is born with a unit of perishable goods. In contrast, each producer is born with no goods, but can produce an amount $f(x)$ of goods when old by investing an amount $x$ of goods when young. The function $f: \mathbf{R}_{+} \rightarrow \mathbf{R}_{+}$is strictly increasing and concave, and satisfies the Inada condition (i.e., $f(0)=0$ and $\lim _{x \downarrow 0} f^{\prime}(x)=\infty$ ). Assume that the marginal return on investment in a producer's production diminishes sufficiently fast that it is never efficient to invest all the goods endowments of young suppliers in producers' production:

$$
f^{\prime}(1)<\rho .
$$

In addition, each producer can produce an amount $g(x)$ of "lemons" when old using an amount $x$ of goods when young. Assume that the function $g: \mathbf{R}_{+} \rightarrow \mathbf{R}_{+}$satisfies 


$$
g(x) \begin{cases}=0 & \text { if } x=0 \\ >f(x) & \text { if } x>0 .\end{cases}
$$

For simplicity, assume that lemons do not generate any utility for any agent. Both producers and suppliers can distinguish goods and lemons. Throughout the paper, there is no asymmetric information among agents.

Assume that

$$
\rho>1
$$

This assumption implies that it is never Pareto-improving for young suppliers to transfer their goods to old agents in the previous cohort. Thus, the economy is dynamically efficient.

\subsection{Equilibrium with perfect contract enforcement by the civil court}

Let us start with no friction in the enforcement of a contract:

Assumption 1 The civil court can distinguish goods and lemons.

In this case, a young producer can write a pledgeable real credit contract with a young supplier, because if an old producer reneges on a promise to repay goods to an old supplier, then the civil court can seize the output of the producer, and distribute it to the supplier. Assume that there exists a competitive real credit market between young producers and suppliers.

With Assumption 1, the model is just a standard overlapping generations model. The utility maximization problem for a young supplier in cohort $t$ is specified as follows:

$$
\begin{aligned}
\max _{\ell_{S, t}} & \rho c_{S, Y, t}+c_{S, O, t+1} \\
\text { s.t. } & c_{S, Y, t}+\ell_{S, t}=1 \\
& c_{S, O, t+1}=\left(1+r_{t}\right) \ell_{S, t} \\
& c_{S, Y, t}, \ell_{S, t}, c_{S, O, t+1} \geq 0
\end{aligned}
$$

for $t=0,1,2, \ldots$, where $\ell_{S, t}$ denotes the amount of goods lent to young producers in period $t$, and $r_{t}$ denotes the competitive real interest rate in the period. The first constraint is the flow-of-fund constraint when the supplier is young, on the righthand side of which is the amount of goods endowment for each young supplier. The second constraint is the flow-of-fund constraint when the supplier is old. The last constraint implies that consumption and lending are non-negative by definition.

Similarly, the utility maximization problem for a young producer in cohort $t$ is as follows: 


$$
\begin{aligned}
\max _{x_{P, t}} & c_{P, O, t+1} \\
\text { s.t. } & c_{P, O, t+1}=f\left(x_{P, t}\right)-\left(1+r_{t}\right) x_{P, t} \\
& x_{P, t}, c_{P, O, t+1} \geq 0,
\end{aligned}
$$

for $t=0,1,2, \ldots$, where the subscript $P$ indicates that the variable for a representative producer, and $x_{P, t}$ denotes the amount of goods that the producer borrows from suppliers and then invests in the producer's production when young. The first constraint is the flow-of-fund constraint when the producer is old. The second constraint implies that investment and consumption are non-negative by definition.

Following the standard definition of a competitive equilibrium, an equilibrium is characterized by the solutions to (5) and (6) and the value of $r_{t}$ satisfying the market clearing condition in the real credit market:

$$
x_{P, t}=\ell_{S, t}
$$

for $t=0,1,2, \ldots$, given the assumption that the measures of producers and suppliers in each cohort are both unity.

Given the dynamic efficiency of the economy as assumed in (4), it is straightforward to show that the marginal rate of return on investment in a producer's production equals the marginal rate of intertemporal substitution for a supplier via the competitive real interest rate in the equilibrium: ${ }^{7}$

Proposition 1 Suppose that Assumption 1 holds. In this case, $x_{P, t}$ and $r_{t}$ satisfy

$$
\begin{gathered}
x_{P, t}=x^{*} \equiv f^{\prime-1}(\rho) \\
1+r_{t}=\rho
\end{gathered}
$$

for $t=0,1,2, \ldots$ in the equilibrium.

\subsection{Autarky with imperfect contract enforcement}

Hereafter, let us assume that the civil court has limited ability to enforce a contract:

Assumption 2 The difference between goods and lemons is unverifiable at the civil court.

The underlying assumption is that goods and lemons are similar enough that the civil court cannot tell the difference between the two. This assumption can be interpreted as reflecting the difficulty in defining different qualities of goods in legal

\footnotetext{
7 Note that given the assumption that the function $f$ is strictly increasing and concave, and satisfies the Inada condition, (2) ensures that the value of $x^{*}$ falls between 0 and 1 . In this case, all the values of $c_{S, Y, t}$, $c_{S, O, t+1}$, and $c_{P, O, t+1}$ are positive in the equilibrium, satisfying the non-negativity constraints.
} 
terms if the goods have similar physical features, because the evaluation of qualities is subjective. Assumption 2 is a stylized assumption to incorporate this kind of difficulty for the civil court. For simplicity, producers and suppliers are assumed to have the same tastes. They can distinguish goods and lemons for their subjective tastes, but cannot verify the difference in an objective manner at the court.

Given this assumption, if a producer entered into a real credit contract with a supplier, then the producer would repay only lemons to the supplier, because it is less costly to produce lemons than goods, as implied by (3). In this case, the supplier would not be able to claim the producer's default at the civil court to seize the goods produced and retained by the producer, as the court would dismiss the supplier's claim, holding that the lemons delivered by the producer fall into the same category of goods that the producer promises to deliver in the contract. Expecting this consequence, no supplier participates in a real credit contract ex-ante. Thus, the economy becomes autarky.

\section{Introducing fiat money and nominal debt}

\subsection{Introducing fiat money}

Let us introduce fiat money into the baseline model. Assume that there are a continuum of the initial old in period 0 , each of which maximizes the consumption of goods in the period. The measure of the initial old is unity. The initial old are endowed with an amount $M(\geq 0)$ of fiat money for each in period 0 . Assume that both agents and the civil court can identify the amount of fiat money correctly. This assumption reflects the fact that the nominal value of fiat money is just a number. Also assume that it is too costly to counterfeit fiat money. The model abstracts from counterfeiting, because existing technology can make it a minor problem, as observed in developed countries.

In addition, assume that there exists a competitive goods market, in which goods and fiat money can be traded. Note that this assumption does not guarantee that fiat money circulates in the economy, as the real value of fiat money in the market can be zero.

\subsection{Pledgeability of nominal debt contracts}

Now suppose that fiat money has a positive real value in the competitive goods market, and also that agents write a nominal debt contract such that a producer receives goods from a supplier when young, and repays fiat money to the supplier when old.

In this case, if a producer fails to repay the promised amount of fiat money, then the supplier in the defaulted contract can ask the civil court to seize all the belongings of the producer, and sell them for fiat money in the competitive goods market. ${ }^{8}$

\footnotetext{
${ }^{8}$ Even though the civil court cannot observe the repayment of fiat money from a producer to a supplier directly, assume that the court can ask a producer to present a receipt received from a supplier as the evidence of debt repayment, if the supplier claims the producer's default on a nominal debt contract. If the court cannot identify a forged receipt, then the court can require a receipt to be certified by a third party
} 
When selling the seized belongings, the civil court does not have to determine which part of the belongings are goods, because agents in the competitive goods market can distinguish goods and lemons, and compete with each other until arbitrage opportunities disappear. ${ }^{9}$ Therefore, the court can receive the competitive nominal price of the defaulting producer's goods from buyers in the market. If the value of nominal debt exceeds the competitive nominal price of goods held by the defaulting producer, then the court simply puts on sale all the producer's belongings, and then returns only lemons, if any, to the producer. Thus, the threat of a court action can eliminate any incentive for a producer to strategically default on nominal debt in any case. $^{10}$

Given the presence of nominal debt contracts, assume that the goods market is split into two segments by the timing of maturity of nominal debt contracts in each period, because old producers must acquire fiat money by selling their output before repaying fiat money to old suppliers, while young suppliers can wait to sell their output after the maturity of nominal debt contracts in the period. Call the first segment of the goods market a "morning goods market", and the second segment an "afternoon goods market". For simplicity, assume that the civil court can sell a defaulting producer's belongings instantly in the morning goods market, so that the nominal price of a defaulting producer's goods is the same regardless of whether the producer or the court sells the goods. ${ }^{11}$

\section{Footnote 8 (continued)}

that intermediates the payments of fiat money, such as a commercial bank providing a bank transfer service. If a supplier refuses to provide a producer with a receipt for the repayment of fiat money, then the court can accept the repayment of fiat money by the producer directly, and pass on the fiat money to the supplier to fulfill the producer's debt on behalf of the producer. Such an arrangement is feasible because the court can identify fiat money correctly, as assumed above. This arrangement corresponds to a deposit of a payment at the court in practice.

9 This feature of the competitive goods market implies that a producer and a supplier can write an enforceable real credit contract such that the producer is obliged to give up all belongings to the supplier when old. Assume that there is an infinitesimally small utility cost for a producer to engage in the production of goods, so that a young producer does not have incentive to enter into such a contract.

10 If there is any reader wondering whether the model characterizes the issuer of fiat money as an agency for consumer protection, the answer is no, because the issuer of fiat money only needs to be tasked with issuing universally identifiable fiat money in the model. This feature of the model is consistent with the fact that the central bank in each country is usually mandated to issue banknotes that are robust to counterfeiting and easy to authenticate. Also, it is legal to trade lemons at any agreed price in the model, given the freedom of contract, which is consistent with the fact that it is legal to trade garbage in reality. Thus, the central bank in the model takes part in the pledgeability of nominal contracts, rather than aiming to prohibit the sales of some types of products by its policy tool.

11 The assumption of sequential goods market transactions is not crucial for the results of the model. It can be shown that the results of the model do not change even if old producers and young suppliers sell goods simultaneously in each period. In this case, the competitive nominal prices of goods sold by the two types of agents can differ from each other, because old producers require the payments of fiat money for their goods to be made before the maturity of nominal debt, while young suppliers can allow late payments of fiat money after the maturity of nominal debt. The pledgeability of nominal debt also remains to hold even if the civil court cannot sell a defaulting producer's belongings in the same period as the maturity of nominal debt, because it can do so in the next period. In this case, a defaulting producer loses the opportunity to consume goods when old; thus, producers have no incentive to default on nominal debt strategically. See Tomura (2020) for more details. As such, the key feature of the goods market in the model is the differentiation of nominal prices of goods for different timings of payments of fiat money, 
Because the morning goods market takes place before the maturity of nominal debt contracts, suppliers must save fiat money when young to buy goods in the morning goods market when old. After the maturity of nominal debt contracts, old suppliers can spend fiat money repaid by old producers in the afternoon goods market. The flow of fiat money with a positive real value is summarized in Table 1.

To clarify, if old producers can borrow fiat money from old suppliers to repay nominal debt, then it is equivalent to postponing the maturity of nominal debt within the same period, which simply delays the timings of the morning goods market and the afternoon goods market in the period. Thus, introducing such an opportunity does not change any result in the model.

\subsection{Each agent's utility maximization problem}

While Table 1 illustrates that young suppliers enter into the afternoon goods market, this is a result of endogenous behavior, rather than an exogenous assumption. Let us denote by $p_{M, t}$ and $p_{A, t}$ the real competitive prices of fiat money in terms of goods in the morning and afternoon goods market, respectively, in period $t$. If $p_{M, t}<p_{A, t}$, then young suppliers would be able to earn free profit by selling their goods for fiat money in the morning goods market and then repurchasing goods with the fiat money in the afternoon goods market. However, because old suppliers can consume goods only before their exit from the economy, they must spend fiat money in the afternoon goods market after receiving the repayment of nominal debt. Thus, there would be no agent selling goods to young suppliers in the afternoon goods market in such a case. Without a loss of generality, suppose that young suppliers enter into the afternoon goods market in each period, given ${ }^{12}$

$$
p_{M, t} \geq p_{A, t}
$$

throughout the paper.

Given the presence of a competitive goods and credit market, no availability of real credit contracts with Assumption 2, and (10), the utility maximization problem for a young supplier in cohort $t$ can be written as follows:

\footnotetext{
Footnote 11 (continued)

rather than sequential goods market transactions per se. This paper assumes sequential goods market transactions to simplify the description of the model. For this purpose, the goods market needs to be split into only two segments, because there are only two distinct timings of payments of fiat money for goods in each period, i.e., before and after the maturity of nominal debt contracts. This feature of the model differs from other models featuring intra-period sequential goods market transactions in the literature, such as Lagos and Wright (2005).

12 Note that if fiat money does not have any value, then $p_{M, t}=p_{A, t}=0$. Thus, (10) holds in both a monetary equilibrium and a non-monetary equilibrium. In addition, formally speaking, the behavior of young suppliers and (10) should be derived after defining an equilibrium with fiat money. I take a short-cut here to avoid replicating Table 1 for the case in which young suppliers enter into the morning goods market and also to simplify the description of the model in the following part of the paper.
} 


$$
\begin{aligned}
\max _{\left\{b_{S, t}, m_{S, t}, m_{S, t+1}^{\prime}\right\}} & \rho c_{S, Y, t}+c_{S, O, t+1} \\
\text { s.t. } & c_{S, Y, t}+q_{t} b_{S, t}+p_{A, t} m_{S, t}=1 \\
& c_{S, O, t+1}=p_{M, t+1} m_{S, t+1}^{\prime}+p_{A, t+1}\left(b_{S, t}+m_{S, t}-m_{S, t+1}^{\prime}\right) \\
& m_{S, t+1}^{\prime} \in\left[0, m_{S, t}\right] \\
& c_{S, Y, t}, b_{S, t}, m_{S, t}, c_{S, O, t+1} \geq 0,
\end{aligned}
$$

where $b_{S, t}$ denotes the face value of nominal debt, i.e., the repayable amount of fiat money, purchased by a representative young supplier in period $t ; q_{t}$ is the competitive real discount price of nominal debt in the period; $m_{S, t}$ is the amount of fiat money held by the supplier at the end of the period; and $m_{S, t+1}^{\prime}$ is the amount of fiat money spent by the supplier in the morning goods market in period $t+1$. Each supplier takes as given $q_{t}, p_{A, t}, p_{A, t+1}$, and $p_{M, t+1}$. The first constraint is the flow-of-fund constraint when the supplier is young, and the second constraint is the flow-of-fund constraint when the supplier is old. ${ }^{13}$

The third constraint is the feasibility constraint on $m_{S, t+1}^{\prime}$, which implies that an old supplier can spend fiat money in the morning goods market only up to the supplier's money holding at the beginning of the period. The last constraint implies that consumption, lending, and a money holding are non-negative by definition.

The utility maximization problem for a young producer in cohort $t$ is as follows:

$$
\begin{aligned}
\max _{x_{P, t}} & c_{P, O, t+1} \\
\text { s.t. } & x_{P, t}=q_{t} b_{P, t} \\
& c_{P, O, t+1}=f\left(x_{P, t}\right)-p_{M, t+1} b_{P, t} \\
& x_{P, t}, b_{P, t}, c_{P, O, t+1} \geq 0,
\end{aligned}
$$

where $b_{P, t}$ denotes the face value of nominal debt issued by a representative young producer in period $t$. The first constraint is the flow-of-fund constraint when the producer is young, and the second constraint is the flow-of-fund constraint when the producer is old. In the second constraint, $p_{M, t+1} b_{P, t}$ is the amount of goods that the producer must sell in the morning goods market to repay nominal debt, $b_{P, t}$. The last constraint implies that investment, borrowing, and consumption are non-negative by definition.

\subsection{Definition of an equilibrium}

With the introduction of fiat money and nominal debt, the market clearing condition in the baseline model, (7), is replaced by

\footnotetext{
${ }^{13}$ Precisely speaking, $p_{A, t}$ in the first constraint in (11), i.e., the real price of fiat money obtained by each young supplier, should be written as $\min \left\{p_{M, t}, p_{A, t}\right\}$, because young suppliers choose the segment of the goods market in which they can acquire fiat money at the lowest cost. In (11), (10) is already substituted into $\min \left\{p_{M, t}, p_{A, t}\right\}$.
} 
Table 1 Flows of goods, nominal debt, and fiat money when fiat money has a positive real value

\begin{tabular}{lllll}
\hline & Period & & \\
\cline { 2 - 4 } & $t$ & $t+1$ & \\
\hline Cohort $t-1$ & Old suppliers & & & \\
Cohort $t$ & $M \downarrow \uparrow G$ & & & \\
& Young suppliers & Old suppliers & Old suppliers & Old suppliers \\
& $I O U_{P} \uparrow \downarrow G$ & $M \downarrow \uparrow G$ & $M \uparrow \downarrow I O U_{P}$ & $\mid \uparrow$ \\
& Young producers & Old producers & Old producers & $M|| G$ \\
& & & & $\downarrow \mid$ \\
Cohort $t+1$ & & & & Young suppliers \\
\hline
\end{tabular}

Each arrow indicates the direction of a transfer. " $M$ " and " $G$ " indicate fiat money and goods, respectively, and " $I O U_{P}$ " indicates nominal debt issued by producers. The first exchange of " $M$ " and " $G$ " between old suppliers and old producers indicates transactions in the morning good market, whereas the second exchange between old suppliers and young suppliers indicates transactions in the afternoon goods market. The exchange between " $G$ " and " $I O U_{P}$ " indicates the lending of goods, and the exchange between " $I O U_{P}$ " and " $M$ " indicates the repayment of nominal debt

$$
\begin{gathered}
m_{S, t+1}=b_{S, t}+m_{S, t}-m_{S, t+1}^{\prime}=M, \\
b_{P, t}=m_{S, t+1}^{\prime}, \\
b_{S, t}=b_{P, t},
\end{gathered}
$$

where $M$ is the amount of fiat money held by the initial old in period 0 as assumed above. The first equation, (13), is the market clearing condition for the afternoon goods market. On the left-hand side of this equation is the amount of fiat money acquired by young suppliers in the market in period $t+1$, whereas the middle part is the amount of fiat money paid by old suppliers in the market in the period. The second equation, (14), is the market clearing condition for the morning goods market, which implies that the amount of fiat money paid by old suppliers in the market, $m_{S, t+1}^{\prime}$, equals the face value of nominal debt repaid by old producers, $b_{S, t}$. The last equation, (15), is the market clearing condition for the credit market. In accordance with the baseline model, an equilibrium is characterized by the solutions to utility maximization problems for the two types of agents, (11) and (12); and the values of $q_{t}, p_{A, t}$, and $p_{M, t+1}$ that satisfy (13)-(15) for $t=0,1,2, \ldots$

Note that $p_{M, t}=p_{A, t}=0$ if fiat money does not have any real value. Thus, (11)-(15) nest the case in which fiat money does not circulate in the economy. In such a case, (11) implies that $q_{t}$ or $b_{S, t}$ is zero; thus, autarky remains an equilibrium. ${ }^{14}$

\footnotetext{
${ }^{14}$ Even though fiat money has a real value once producers issue nominal debt, autarky with a zero real value of fiat money remains an equilibrium, because agents take as given the competitive real prices of fiat money in the two segments of the goods market in each period.
} 


\subsection{Monetary steady state}

Now let us show the existence of a monetary steady state such that fiat money has positive constant real values in the morning and afternoon goods market in each period, i.e., $p_{M, t}=p_{M, t+1}>0$ and $p_{A, t}=p_{A, t+1}>0$ for all $t$, in an equilibrium. The following proposition holds: ${ }^{15}$

Proposition 2 Suppose Assumption 2 holds and $M>0$. In this case, there exists a monetary steady state such that

$$
\begin{gathered}
x_{P, t}=x^{* *} \equiv f^{\prime-1}\left(\rho^{2}\right) \\
\left(q_{t}, p_{A, t}, p_{M, t+1}\right)=\left(\frac{x^{* *}}{M}, \frac{\rho x^{* *}}{M}, \frac{\rho^{2} x^{* *}}{M}\right) \\
b_{S, t}=b_{P, t}=m_{S, t}=m_{S, t+1}^{\prime}=M \\
\left(c_{P, O, t+1}, c_{S, Y, t}, c_{S, O, t+1}\right)=\left(f\left(x^{* *}\right)-\rho^{2} x^{* *}, 1-(1+\rho) x^{* *},\left(\rho+\rho^{2}\right) x^{* *}\right) \\
\text { for } t=0,1,2, \ldots, \text { if and only if } x^{* *} \leq(1+\rho)^{-1} .
\end{gathered}
$$

Proof The value of $q_{t}$ must be positive in a monetary steady state, as otherwise suppliers would buy an infinite face value of nominal debt in the credit market, given a positive real price of fiat money. Given $q_{t}>0$, the first-order condition for the amount of investment by a young producer, $x_{P, t}$, in (12) implies that

$$
f^{\prime}\left(x_{P, t}\right)=\frac{p_{M, t+1}}{q_{t}} .
$$

Because $p_{M, t+1}$ is finite in a monetary steady state, this equation implies that the value of $x_{P, t}$ is positive in a monetary steady state. Thus, the discounted value of nominal debt issued by a young producer, $b_{P, t}$, is also positive, given $q_{t} b_{P, t}=x_{P, t}$ as implied by the first constraint in (12) and $q_{t}>0$ in a monetary steady state. Therefore, the amount of fiat money paid by an old supplier to old producers, $m_{S, t+1}^{\prime}$, and the amount of fiat money repaid to an old supplier, $b_{S, t}$, are positive, given $m_{S, t+1}^{\prime}=b_{S, t}=b_{P, t}>0$ as implied by (14) and (15). Also, an old supplier holds a positive amount of fiat money at the beginning of each period, i.e., $m_{S, t}=M>0$, as implied by (13). With these results, the second and third constraint in (11) imply that an old supplier's consumption $c_{S, O, t+1}$, is positive, given $b_{S, t}>0$ and $m_{S, t}>0$, and $p_{A, t+1}>0$ and $p_{M, t+1}>0$ in a monetary steady state.

\footnotetext{
${ }^{15}$ Note that $p_{M, 0}$ does not exist because the initial old in period 0 only participate in the afternoon goods market with their endowment of fiat money.
} 
Given $m_{S, t}>0, m_{S, t+1}^{\prime}=b_{S, t}>0$, and $c_{S, O, t+1}>0$, the first-order conditions for $c_{S, Y, t}, m_{S, t}, m_{S, t+1}^{\prime}$, and $b_{S, t}$ in (11) imply that

$$
\begin{gathered}
\rho-\eta_{t}+\phi_{t}=0, \\
-\eta_{t} p_{A, t}+p_{A, t+1}+\lambda_{t+1}=0, \\
p_{M, t+1}-p_{A, t+1}-\lambda_{t+1}=0, \\
-\eta_{t} q_{t}+p_{A, t+1}=0,
\end{gathered}
$$

respectively, where $\eta_{t}, \phi_{t}$, and $\lambda_{t+1}$ are Lagrange multipliers for $c_{S, Y, t}+q_{t} b_{S, t}+p_{A, t} m_{S, t}=1, c_{S, Y, t} \geq 0$, and $m_{S, t+1}^{\prime} \leq m_{S, t}$, respectively. Because (21) implies $\phi_{t}=\eta_{t}-\rho \geq 0$, (22) implies

$$
\lambda_{t+1}=\eta_{t} p_{A, t}-p_{A, t+1} \geq(\rho-1) p_{A, t}>0
$$

given (4) and $p_{A, t}=p_{A, t+1}>0$ in a monetary steady state. Thus, $m_{S, t+1}^{\prime}=m_{S, t}$ - that is, old suppliers spend all the fiat money holdings at the beginning of the period in the morning goods market. Therefore, (13)-(15) imply $m_{S, t}=m_{S, t+1}^{\prime}=b_{S, t}=b_{P, t}=M$, i.e., (18), which means that the fixed-supplied fiat money acquired by old producers in the morning goods market is repaid to old suppliers, and then paid to young suppliers in the next cohort in the afternoon goods market in each period.

Now suppose $c_{S, Y, t}>0$. In this case, $\phi_{t}=0$ and $\eta_{t}=\rho$. Then, given $p_{A, t}=p_{A, t+1}$ in a monetary steady state, eliminating $\lambda_{t+1}$ from (22) and (23) yields $p_{M, t+1}=\rho p_{A, t+1}$. Substituting this equation and (24) into (20) in turn yields $f^{\prime}\left(x_{P, t}\right)=\rho^{2}$. Therefore, $q_{t} M=x_{P, t}$, because $q_{t} b_{P, t}=x_{P, t}$ as implied by the first constraint in (12) and $b_{P, t}=M$ as implied by (18). Given this value of $q_{t}$, the values of $p_{A, t}$ and $p_{M, t+1}$ can be derived from (24) and $p_{M, t+1}=\rho p_{A, t+1}$.

In this case, the values of consumption in (19) are derived from the flow-of-fund constraints in (11) and (12). These solutions are valid if $c_{P, O, t+1}=f\left(x^{* *}\right)-\rho^{2} x^{* *} \geq 0$ and $c_{S, Y, t}=1-(1+\rho) x^{* *} \geq 0$. The former is always satisfied because of the strict concavity of the function $f$. Thus, if and only if $x^{* *} \leq(1+\rho)^{-1}$, there is a monetary steady state with $c_{S, Y, t}>0$ as shown above.

Proposition 2 implies that if $x^{* *}>(1+\rho)^{-1}$, then there is no monetary steady state with $c_{S, Y, t}>0$. In this case, the following assumption is sufficient for the existence of a monetary steady state with $c_{S, Y, t}=0$.

Assumption 3 Suppose that the function $f$ satisfies the following properties:

$$
\begin{aligned}
& \lim _{x \rightarrow 0} \frac{\left(x^{-1}-1\right)^{2}}{f^{\prime}(x)}>1 \\
& \quad \frac{d}{d x}\left\{\left(\frac{1}{x}-1\right)^{2}\right\}<f^{\prime \prime}(x) \quad \text { for all } x \in\left(0, \frac{1}{1+\rho}\right) .
\end{aligned}
$$


Proposition 3 Suppose Assumptions 2 and 3 hold, and $M>0$. If $x^{* *}>(1+\rho)^{-1}$, then there exists a unique monetary steady state such that

$$
\begin{gathered}
x_{P, t}=\hat{x} \text { such that } f^{\prime}(\hat{x})=\left(\frac{1}{\hat{x}}-1\right)^{2} \\
\left(q_{t}, p_{A, t}, p_{M, t}\right)=\left(\frac{\hat{x}}{M},\left(\frac{1}{\hat{x}}-1\right) q_{t},\left(\frac{1}{\hat{x}}-1\right)^{2} q_{t}\right) \\
\left(c_{P, O, t+1}, c_{S, Y, t}, c_{S, O, t+1}\right)=\left(f(\hat{x})-\frac{p_{M, t+1} \hat{x}}{q_{t}}, 0,\left(p_{M, t+1}+p_{A, t+1}\right) M\right)
\end{gathered}
$$

and (18) holds for $t=0,1,2, \ldots$, where $\hat{x} \in\left(0,(1+\rho)^{-1}\right)$.

Proof See Appendix A.

Assumption 3 is a single-crossing condition between $\left(x^{-1}-1\right)^{2}$ and $f^{\prime}(x)$ for $x \in\left(0,(1+\rho)^{-1}\right)$, which ensures the existence of a unique value of $\hat{x} \in\left(0,(1+\rho)^{-1}\right)$ that satisfies (26), given $x^{* *}>(1+\rho)^{-1} \cdot{ }^{16}$

Propositions 2 and 3 demonstrate that imperfect contract enforcement by the civil court can make fiat money circulate endogenously, despite the dynamic efficiency of the economy implied by (2). If young producers issue nominal debt, then young suppliers expect that old producers are willing to sell their output for fiat money to repay nominal debt in the next period, given the pledgeability of nominal debt contracts as described in Sect. 3.2. This expectation of a positive real value of fiat money in the next period in turn provides incentive for young suppliers to sell goods for nominal debt issued by young producers. Thus, fiat money circulates as both a debt-repayment instrument and a payment instrument in the goods market, as illustrated by Table 1 .

\footnotetext{
${ }^{16}$ For example, if $f(x)=A x^{\sigma}$, where $\sigma \in(0,1)$, then the first condition in Assumption 3 is satisfied for all $A>0$, and the second condition is satisfied if and only if $A \in\left(0,2 \rho(1+\rho)^{\sigma} /[\sigma(1-\sigma)]\right)$. Thus, Assumption 3 is compatible with a standard production function in macroeconomics. Also, $x^{* *}>(1+\rho)^{-1}$ is satisfied if and only if $A \sigma(1+\rho)^{1-\sigma}>\rho^{2}$. Therefore, Proposition 3 is relevant for $A \in\left(\rho^{2} /\left[\sigma(1+\rho)^{1-\sigma}\right], 2 \rho(1+\rho)^{\sigma} /[\sigma(1-\sigma)]\right)$, which is not empty, given (4). In this case, it can be shown that there is no monetary steady state with $c_{S, Y, t}=0$ if $x^{* *}<(1+\rho)^{-1}$; thus Propositions 2 and 3 imply that there always exists a unique monetary steady state. A caveat is that Assumption 3 does not set any condition on $f(x)$ for $x \geq(1+\rho)^{-1}$. Thus, if the functional form of $f$ is manipulated so that (26) has a root for $\hat{x}$ in $\left((1+\rho)^{-1}, 1\right)$, then there can be a monetary steady state with $c_{S, Y, t}=0$, even if $x^{* *}<(1+\rho)^{-1}$. Note that the upper bound on the domain of $\hat{x}$ is set to 1 here, because each young supplier is born with only a unit of goods. Thus, it is impossible to have $\hat{x}>1$ in an equilibrium. The analysis of multiple monetary steady states is outside the focus of this paper.
} 


\subsection{Underinvestment in a monetary steady state}

Given the strict concavity of the production function $f$, comparison between (8) and (16) implies that the values of investment in producers' production in monetary steady states described above are smaller than that in the baseline model without limited ability of the civil court, given (4):

$$
x^{*}>x^{* *}>\hat{x},
$$

where the second inequality holds for the monetary steady state with no young suppliers' consumption, because $\hat{x}<(1+\rho)^{-1}$ given $x^{* *}>(1+\rho)^{-1}$. This result can be regarded as underinvestment in producers' production for each cohort, as it implies that the marginal rate of return on investment in producers' production, $f^{\prime}\left(x_{P, t}\right)$, is higher than the marginal rate of intertemporal substitution, $\rho .{ }^{17}$

To see the reason for this result, note that a monetary steady state requires old suppliers to hold fiat money at the beginning of each period, so that old producers can obtain fiat money to repay nominal debt by selling goods to old suppliers in the morning goods market. This requirement implies that young suppliers must save fiat money by selling goods to old suppliers in the previous cohort in each period, as illustrated by Table 1 . To do so, however, young suppliers must forego consumption despite the dynamic efficiency of the economy, as implied by (4). To compensate for this opportunity cost, the real price of fiat money for old suppliers in the morning goods market must be sufficiently high to raise the rate of return on intertemporal money holdings for young suppliers. As a result, the real price of fiat money in the morning goods market becomes higher than that in the afternoon goods market:

$$
p_{M, t}>p_{A, t}
$$

as indicated by (17) in Proposition 2. Arbitrage does not make the two nominal prices of goods equal, as young suppliers are better off by selling their goods for fiat money at a higher nominal goods price in the afternoon goods market (i.e., $1 / p_{A, t}$ ), while old producers must sell their goods for fiat money in the morning goods market to meet the maturity of nominal debt. A higher real value of fiat money spent by old suppliers in turn lowers the rate of return on young producers' investment in production, because producers must acquire fiat money from old suppliers to repay nominal debt when they are old. As a result, young producers reduce their investment in production.

To clarify, this result is not an artificial result due to sequential goods market transactions in the two segments of the goods market in each period. Even if it is assumed that old producers and young suppliers sell their goods simultaneously before the maturity of nominal debt, young suppliers can accept late payments after

\footnotetext{
17 The baseline model attains the social optimum if social welfare in a monetary steady state is defined by aggregate consumption in each period. This definition is equivalent to giving an equal weight to the utility of each cohort in the definition of social welfare, as the relative utility weight for the initial old becomes zero compared with the sum of weights for subsequent cohorts.
} 
the maturity of nominal debt, which results in the same separation of goods prices as shown in (30). ${ }^{18}$

\subsection{Shortage of real money balances for debt repayments in a monetary steady state}

The opportunity cost of intertemporal money holdings can be eliminated if the central bank adopts the Friedman rule by retiring the supply of fiat money at such a rate that the real rate of return on fiat money equals the marginal rate of intertemporal substitution, $\rho$. It can be shown that if the value of investment in producers' production in the baseline model, $x^{*}$, is not too large, then the Friedman rule results in $p_{M, t}=p_{A, t}$ and prevents underinvestment. See Appendix B for the formal characterization of the monetary steady state with the Friedman rule.

However, it can be also shown that even with the Friedman rule, underinvestment can occur due to a shortage of real money balances for debt repayments in a monetary steady state, if the value of $x^{*}$ is sufficiently large. To illustrate this result, let us show a similar result using the model described above, given the fixed supply of fiat money. Note that (10), (20), (21), and (24) jointly imply that if $x_{P, t}=x^{*}$ in a monetary steady state, then it is necessary that $p_{M, t}=p_{A, t}$ and $\eta_{t}=\rho$, where $\eta_{t}$ is the Lagrange multiplier for the first constraint in (11). ${ }^{19}$ Now let us suppose $p_{M, t}=p_{A, t}$ and $\eta_{t}=\rho$ in a monetary steady state, and then show that $x_{P, t}=x^{*}$ is incompatible with this conjecture if $x^{*}$ is too large.

The market clearing condition for the morning goods market, (14), implies that the face value of nominal debt issued by a young producer, $b_{P, t}$, must equal the amount of fiat money that an old supplier pays for old producers' goods in the next period, $m_{S, t+1}^{\prime}$. Therefore, given the market clearing condition for the credit market, (15), and the feasibility constraint on $m_{S, t+1}^{\prime}$ in (11), the face value of nominal debt purchased by a young supplier, $b_{S, t}$, is capped by the amount of fiat money held by an old supplier at the beginning of the next period, $m_{S, t}$, in an equilibrium:

$$
b_{S, t} \leq m_{S, t} \text {. }
$$

Because the real discount price of nominal debt, $q_{t}$, equals the present discounted real value of nominal debt for young suppliers, $p_{A, t+1} / \rho$, as indicated by $\eta_{t}=\rho$ and (24), (31) implies an upper bound on the real discount value of nominal debt:

$$
q_{t} b_{S, t} \leq \frac{p_{A, t} m_{S, t}}{\rho}
$$

given $p_{A, t}=p_{A, t+1}$ in a monetary steady state.

\footnotetext{
18 Note that old suppliers buy goods on credit in this case, which is nominal debt. Thus, the civil court can enforce old suppliers' promises to pay late. See Tomura (2020) for more details.

19 Given $\phi_{t} \geq 0$, (20), (21), and (24) imply $p_{A, t+1}=\eta_{t} q_{t} \geq p_{M, t+1}=\rho q_{t}$ if $f^{\prime}\left(x_{P, t}\right)=\rho$. Given (10), $\eta_{t}=\rho$ and $p_{M, t}=p_{A, t}$ in a monetary steady state in this case. A similar result holds with the Friedman rule, as shown in Appendix B.
} 
The flow-of-fund constraint for a young supplier, i.e., the first constraint in (11), implies that each young supplier must allocate a unit of goods to the acquisition of fiat money from old suppliers and the lending of goods for young producers' investment in production:

$$
c_{S, Y, t}+q_{t} b_{S, t}+p_{A, t} m_{S, t}=1
$$

where $c_{S, Y, t}, q_{t} b_{S, t}$, and $p_{A, t} m_{S, t}$ are the amounts of goods allocated to consumption, the lending to young producers, and the acquisition of fiat money from old suppliers, respectively, by a young supplier. Therefore, given consumption being non-negative by definition, substituting $c_{S, Y, t} \geq 0$ and (32) into (33) yields

$$
q_{t} b_{S, t} \leq \frac{1}{1+\rho} .
$$

Because $q_{t} b_{S, t}$ equals the amount of a young producer's investment in production, $x_{P, t}$, as implied by the first constraint in (12) and the market clearing condition for the credit market, (15), (34) indicates that $x_{P, t}=x^{*}$ is incompatible with $p_{M, t}=p_{A, t}$ and $\eta_{t}=\rho$, if $x^{*}$ is greater than the right-hand side of (34).

This result illustrates that if the value of investment by young producers in the baseline model, $x^{*}$, is too large, then it cannot be implemented in a monetary steady state, because the real value of fiat money that old producers can repay is insufficient to give incentive for young suppliers to lend such a large value of goods to young producers. This shortage of real money balances for debt repayments would reduce young producers' investment to a feasible level, even in the absence of the opportunity cost for intertemporal money holdings.

\section{Introducing the central bank's discount window}

Underinvestment described above can be prevented if the central bank opens a discount window for old suppliers within each period. To confirm this result, let us introduce the following assumption:

Assumption 4 Each old supplier can borrow fiat money from the central bank at a zero intra-period interest rate up to the face value of nominal debt that the supplier holds at the beginning of each period. Each loan matures by the end of the same period.

This assumption can be interpreted as a standard intraday liquidity facility offered by the central bank in practice, such as intraday overdrafts of bank reserves for commercial banks. ${ }^{20}$ Only the intra-period lending of fiat money by the central bank is

\footnotetext{
${ }^{20}$ Commercial banks hold bank reserves for the settlements of bank transfers in practice. Bank deposits can be introduced into the model without any significant change. For example, suppose that young suppliers can swap nominal debt issued by young producers for bank deposits issued by commercial banks at par value in each period. This transaction corresponds to bill discounting by commercial banks in practice. Old suppliers can pay deposit balances for old producers' output, while old producers can repay nominal debt by received deposit balances. In addition, assume that commercial banks pay fiat money,
} 
considered here, so that the supply of fiat money through this lending is separated from the fixed supply of fiat money considered in the previous section, which is intertemporal.

This assumption changes the utility maximization problem for a young supplier, (11), in such a way that the constraint on the amount of fiat money that an old supplier can spend in the morning goods market, i.e., $m_{S, t+1}^{\prime} \in\left[0, m_{S, t}\right]$, is replaced by

$$
m_{S, t+1}^{\prime} \in\left[0, m_{S, t}+b_{S, t}\right],
$$

where $b_{S, t}$ is the face value of nominal debt held by the supplier at the beginning of period $t$. The other part of the model remains the same. ${ }^{21}$ Note that an old supplier's intra-period liability to the central bank is nominal debt. Thus, the civil court can enforce the repayment of the liability as described in Sect. 3.2. Table 2 summarizes the flow of fiat money with a positive real value under Assumption 4.

The following proposition summarizes the monetary steady state with Assumption 4:

Proposition 4 Suppose that Assumptions 2 and 4 hold. Then a monetary steady state exists if and only if $M=0$. In this case,

$$
\begin{gathered}
x_{P, t}=x^{*} \\
p_{M, t+1}=\rho q_{t} \\
b_{S, t}=b_{P, t}=m_{S, t+1}^{\prime}=\frac{x^{*}}{q_{t}} \\
m_{S, t}=0 \\
\left(c_{P, O, t+1}, c_{S, Y, t}, c_{S, O, t+1}\right)=\left(f\left(x^{*}\right)-\rho x^{*}, 1-x^{*}, \rho x^{*}\right)
\end{gathered}
$$

for $t=0,1,2, \ldots$ in the monetary steady state. The monetary steady state values of $q_{t}$ and $p_{A, t}$ are indeterminate, except that $q_{t}>0$ and $p_{A, t} \in\left[q_{t}, \rho q_{t}\right]$ for $t=0,1,2, \ldots$

Proof See Appendix C.

Footnote 20 (continued)

which corresponds to bank reserves, to each other to settle the transfers of deposit balances from old suppliers to old producers. Assume that commercial banks can borrow fiat money from the central bank within each period by asking the central bank to discount their holdings of nominal debt owed by old producers at a zero intra-period interest rate.

21 There is no need for an explicit market clearing condition for the central bank's discount window lending, as the central bank accommodates demand for the lending from old suppliers passively at a zero intra-period interest rate. 
Note that $c_{P, O, t+1} \geq 0$ and $c_{S, Y, t} \geq 0$ are satisfied in (40), because of the strict concavity of the production function $f$ and (2), respectively. This proposition demonstrates that introducing the central bank's discount window lending makes the value of investment in producers' production, $x_{P, t}$, equal to the value in the baseline model without limited ability of the civil court. In this case, old suppliers can spend fiat money in the morning goods market up to the face value of nominal debt they hold, because they can borrow fiat money up to this value through the central bank's discount window within each period. Thus, young suppliers do not need to save fiat money, or require compensation for the opportunity cost of intertemporal money holdings. Furthermore, young producers can promise to repay any face value of nominal debt, i.e., $b_{P, t}$, without an upper bound. Hence, young producers can increase the amount of their investment until the marginal rate of return on the investment, $f^{\prime}\left(x_{P, t}\right)$, equals the marginal rate of intertemporal substitution for young suppliers, $\rho$. This result implies that characterizing fiat money as a debt-repayment instrument recognizable by the civil court can explain not only the circulation of fiat money, but also the need for a standard discount window policy of the central bank in practice.

Because young suppliers do not save fiat money, the intertemporal supply of fiat money, $M$, must be set to zero in this monetary steady state, as indicated by Proposition 4. Thus, there is no transfer of goods between different cohorts. Even though the initial old do not receive any goods from young suppliers in cohort 0 in this case, this is the same as in the baseline model without fiat money. Thus, the initial old do not suffer a utility loss even if fiat money is introduced into the baseline model with the central bank's discount window, while the subsequent cohorts are better off by having the marginal rate of return on investment equal to the marginal rate of intertemporal substitution in a monetary steady state.

\subsection{Discussion: can private institutions supply fiat money on behalf of the central bank?}

In this section, it has been assumed that fiat money is issued by a benevolent central bank. Can private institutions supply fiat money on behalf of the central bank? If there is a collusion or oligopoly among private institutions, then private institutions issuing fiat money will discount nominal debt submitted by old suppliers at a positive intra-period interest rate, while buying goods in the goods market. This goods purchase will supply fiat money that old suppliers need to acquire to pay intra-period interest on discount window lending. ${ }^{22}$ In this case, there will occur a gap between the marginal rate of return on investment and the marginal rate of intertemporal substitution. This result is similar to the result of Freeman's (1996b) analysis on the over-issuance of fiat money by private clearing houses.

\footnotetext{
${ }^{22}$ In this case, old producers will be able to obtain fiat money worth the face value of nominal debt by selling their goods in the goods market, and then repay the fiat money to old suppliers. Old suppliers will in turn repay the fiat money to repay discount window lending with interest.
} 
Table 2 Flow of fiat money with discount window lending by the central bank

Period

$t+1$

Cohort $t-1 \quad$ Old suppliers

$\mathrm{I} \uparrow$

$M|| G$

$\downarrow 1$

Cohort $t$

Young suppliers

$I O U_{P} \uparrow \downarrow G$

Young producers

Cohort $t+1$
Central bank $M^{\prime} \downarrow \uparrow I O U_{P}$

Old suppliers

$M+M^{\prime} \downarrow \uparrow G$

Old producers
Central bank

$M^{\prime} \uparrow \downarrow I O U_{P}$

Old suppliers

Old suppliers

$M+M^{\prime} \uparrow \downarrow I O U_{P}$

Old producers
I

$M|| G$

$\downarrow \mid$

Young suppliers

Each arrow indicates the direction of a transfer. " $G$ " indicates goods; " $M$ " and " $M$ " indicate the fixed intertemporal supply of fiat money and the fiat money lent by the central bank within each period, respectively; and " $I O U_{P}$ " indicates nominal debt issued by producers. The exchange between " $M+M^{\prime}$ " and " $G$ " indicates transactions in the morning good market, whereas the exchange between " $M$ " and " $G$ " indicates those in the afternoon goods market. The exchange between " $G$ " and " $I O U_{P}$ " indicates the lending of fiat money, and the exchange between "IOU $U_{P}$ " and " $M+M^{\prime \prime}$ " indicates the repayment of nominal debt. The two exchanges between " $I O U_{P}$ " and " $M^{\prime \prime}$ " indicate the lending and the repayment of fiat money associated with the central bank's intra-period lending

If private institutions can enter into the discount window lending market freely, then it will bring the intra-period interest rate down to zero by a zero-profit condition. ${ }^{23}$ In this case, however, market discipline will not work to ensure that the market value of fiat money issued by private institutions is determined by the face value of nominal debt discounted by them, because the market value of fiat money will depend on the evaluation of fiat money at the civil court, rather than the evaluation of fiat money by fully-informed private agents in the market. ${ }^{24}$ If the civil court accepts fiat money at an inflated value due to its limited ability to monitor the asset holdings of private institutions, then private institutions will be able to issue fiat money to earn seigniorage until the real value of fiat money goes to zero. ${ }^{25}$

\footnotetext{
23 This case corresponds to free banking in Scotland and the U.S. in history, in which banks could issue banknotes without charters if they satisfied a set of requirements set by the government.

24 This feature of the model contrasts with Green's (1997) analysis of Freeman's (1996a) model. This model features a dynamically inefficient economy with an exogenous intertemporal supply of fiat money. Thus, the real value of fiat money is determined solely by private agents. As explained by Green, private institutions can replace the role of the central bank in discount window lending in Freeman's model, because they can issue intermediated debt backed by nominal debt as a substitute to fiat money. In this case, the market value of intermediated debt is evaluated by private agents selling goods for fiat money and intermediated debt. Hence, if the face value of intermediate debt is not matched with the face value of nominal debt discounted by private institutions, then the sellers of goods discount the market value of intermediated debt in terms of fiat money appropriately. This market discipline makes it impossible for private institutions to issue intermediated debt at a higher nominal value than the face value of nominal debt discounted by them.

25 In this case, private institutions will be able to issue fiat money to buy goods for their own consumption without receiving the same face value of nominal debt from old suppliers.
} 
To prevent such a collapse of a monetary steady state, the government will have to set such a regulation that private institutions can issue fiat money only up to the face value of nominal debt they discount. ${ }^{26}$ If it is costly to impose such a regulation on freely entering private institutions perfectly, then it may be more cost-efficient to set up a public institution with a sufficiently rigid governance structure, and make this institution issue fiat money as the central bank. In both cases, it will be efficient to avoid the duplication of effort to monitor the issuers of fiat money by different branches of the government. One way to do so is to introduce such a law that the court can always accept fiat money at the face value, so that the court does not have to monitor the issuers of fiat money. This solution is equivalent to give fiat money legal-tender status.

A caveat is that this solution removes market discipline on the issuers of fiat money completely. Thus, it may not be suitable for private issuers of fiat money, unless the government can monitor them perfectly. In case of founding a central bank, there is no market discipline on a public institution from the beginning. Hence, there is no such trade-off between legal tender status and market discipline in that case.

Overall, the model implies that the best issuers of fiat money are determined by comparison among three factors: a bias on investment created by the market power of private issuers of fiat money, the cost to implement a necessary regulation to allow the free entry of private issuers of fiat money, and the cost to set up a central bank with a necessary governance structure.

\section{Conclusion}

This paper shows in an overlapping generations model that if the civil court cannot distinguish different qualities of goods of the same kind, then it leads to the use of nominal debt contracts as well as the use of fiat money as a means of payment for goods. The model further shows that underinvestment can occur due to the opportunity cost of intertemporal money holdings and a shortage of real money balances for debt repayments. This problem can be resolved if the central bank lends fiat money elastically through a discount window at a zero interest rate within each period.

These results demonstrate that characterizing fiat money as a debt-repayment instrument recognizable by the civil court can explain both the circulation of fiat money in the economy and the need for a standard discount window policy implemented by the central bank in practice. This implication of the model is consistent with the fact that fiat money, i.e., inconvertible money, tends to be designated as legal tender by law and issued by the central bank in each country. Thus, the model replicates two institutional features of the current monetary system-that is, fiat money being legal tender and a discount window offered by the central bank-in an unified framework.

$\overline{{ }^{26}}$ This is equivalent to the real-bills doctrine. See Sargent and Wallace (1982) for more details. 
The model also implies that if the underlying friction for the current use of fiat money is the need for a debt-repayment instrument recognizable by the civil court, then a private money, such as a cryptocurrency, will not substitute legal currencies automatically, because legal tender is set by law in each country. In this case, a private money's success will hinge on whether it can substitute the role of the civil court in contract enforcement. This implication of the model contrasts with the implication of the standard theory of money, which indicates that the existence of a monetary equilibrium is spontaneous, and does not rest on the power of law in each country. Further analysis of the relationship between money and the power of law is left for research.

Another remaining issue is that the model incorporates the limited ability of the civil court by a rather stylized assumption on an unverifiable difference between goods and lemons. This approach is for simplicity. It is left for future research to generalize the limited ability of the civil court, such as randomness in the civil court's interpretation of qualitative statements in a contract, and investigate the need for fiat money in such a set-up.

Also, Proposition 4 implies that the price level becomes indeterminate if the central bank's discount window lending obviates the need for intertemporal money holdings. This result is similar to the finding of Smith (2002) in a spatial-economy model with an intra-period discount window offered by the central bank. Even though Smith interprets price indeterminacy as instability, this result also implies that a monetary economy can be compatible with a nominal anchor for the longrun price level other than the money supply. The analysis of a nominal anchor in an economy with an intra-period discount window, which is a standard central-bank policy in practice, is left for future research.

Acknowledgements Hajime Tomura thanks Tomoyuki Nakajima for his discussion of an earlier version of the paper, and participants in various seminars for their comments. Hajime Tomura is also grateful for financial support from JSPS Grant-in-Aid for Scientific Research (16K03756, 20K01780).

Open Access This article is licensed under a Creative Commons Attribution 4.0 International License, which permits use, sharing, adaptation, distribution and reproduction in any medium or format, as long as you give appropriate credit to the original author(s) and the source, provide a link to the Creative Commons licence, and indicate if changes were made. The images or other third party material in this article are included in the article's Creative Commons licence, unless indicated otherwise in a credit line to the material. If material is not included in the article's Creative Commons licence and your intended use is not permitted by statutory regulation or exceeds the permitted use, you will need to obtain permission directly from the copyright holder. To view a copy of this licence, visit http://creativecommons.org/licen ses/by/4.0/.

\section{Appendix A: Proof of Proposition 3}

The proof of Proposition 2 remains valid. Now suppose that $1-(1+\rho) x^{* *}<0$. In this case, $c_{S, Y, t}>0$ cannot happen in a monetary steady state, as implied by Proposition 2 . Thus, $c_{S, Y, t}=0$ if a monetary steady state exists in this case. In this case, the first constraints in (11) and (12) imply that 


$$
p_{A, t} m_{S, t}=1-q_{t} b_{S, t}=1-x_{P, t} .
$$

Given $p_{A, t}=p_{A, t+1}$ in a monetary steady state and

$$
\eta_{t}=\frac{p_{M, t+1}}{p_{A, t}}=\frac{p_{A, t+1}}{q_{t}}
$$

as implied by (22)-(24), (20) can rewritten as

$$
\begin{gathered}
f^{\prime}\left(x_{P, t}\right)=\frac{p_{M, t+1}}{p_{A, t}} \cdot \frac{p_{A, t}}{q_{t}} \\
=\left(\frac{p_{A, t}}{q_{t}}\right)^{2} \\
=\left(\frac{p_{A, t} M}{q_{t} M}\right)^{2} \\
=\left(\frac{1-x_{P, t}}{x_{P, t}}\right)^{2},
\end{gathered}
$$

where the second equality is implied by (A.2); and the fourth equality is implied by (18), (A.1), and $q_{t} b_{P, t}=x_{P, t}$. This equation confirms (26), and also implies (27) in the proposition, given (20) and $p_{M, t}=p_{M, t+1}$ in a monetary steady state.

Note that Assumption 3 is a single crossing condition for the two sides of (A.5) for $x_{P, t} \in\left(0,(1+\rho)^{-1}\right)$. Thus, there exists a unique value of $x_{P, t} \in\left(0,(1+\rho)^{-1}\right)$ that solves (A.5), if and only if $f^{\prime}\left((1+\rho)^{-1}\right)>\rho^{2}$, i.e., $1-(1+\rho) x^{* *}<0$. Hence, there exists a unique monetary steady state in this case. The values of $c_{P, O, t+1}$ and $c_{S, O, t+1}$ in (28) are derived from the flow-of-fund constraints in (11) and (12). In this case, the value of $c_{P, O, t+1}$ is positive because of the strict concavity of the function $f$.

\section{Appendix B: Monetary steady state with money growth}

Given that the initial old are endowed with an amount $M_{0}(\geq 0)$ of fiat money in period 0 , suppose that the central bank imposes a lump-sum transfer of fiat money to, or from, each old supplier from period 1 onward so that

$$
M_{t}=\gamma M_{t-1}
$$

for $t=1,2,3, \ldots$, where $\gamma>0$ and $M_{t}$ is the total supply of fiat money at the beginning of period $t$.

With a lump-sum transfer by the central bank, the utility maximization problem for a young supplier in cohort $t,(11)$, is modified as follows: 


$$
\begin{aligned}
\max _{\left\{b_{S, t}, m_{S, t}, m_{S, t+1}^{\prime}\right\}} & \rho c_{S, Y, t}+c_{S, O, t+1} \\
\text { s.t. } & c_{S, Y, t}+q_{t} b_{S, t}+p_{A, t} m_{S, t}=1 \\
& c_{S, O, t+1}=p_{M, t+1} m_{S, t+1}^{\prime}+p_{A, t+1}\left(b_{S, t}+m_{S, t}+\tau_{S, t+1}-m_{S, t+1}^{\prime}\right) \\
& m_{S, t+1}^{\prime} \in\left[0, m_{S, t}+\tau_{S, t+1}\right] \\
& c_{S, Y, t}, b_{S, t}, m_{S, t}, c_{S, O, t+1} \geq 0
\end{aligned}
$$

where $\tau_{S, t+1}$ is a lump-sum transfer of fiat money from, or to, an old supplier in period $t+1$, which is a tax if it is negative and a subsidy if it is positive. Thus, $m_{S, t}+\tau_{S, t+1}$ equals the amount of fiat money held by an old supplier at the beginning of period $t+1$.

The utility maximization problem for a young producer in cohort $t$ remains the same as (12). The market clearing condition for the afternoon goods market, (13), is modified as follows:

$$
m_{S, t}= \begin{cases}M_{0} & \text { if } t=0 \\ b_{S, t-1}+m_{S, t-1}+\tau_{S, t}-m_{S, t}^{\prime} & \text { if } t=1,2,3, \ldots\end{cases}
$$

for $t=0,1,2, \ldots$, where (A.8) for $t=1,2,3, \ldots$ implies that the amount of fiat money acquired by young suppliers must equal the amount of fiat money that old suppliers pay in the afternoon goods market. An equilibrium is characterized by the solutions to (12) and (A.7), given $q_{t}, p_{A, t}, p_{A, t+1}$, and $p_{M, t+1}$, and the values of $q_{t}, p_{A, t}$, and $p_{M, t+1}$ that satisfy (14), (15), and (A.8) for $t=0,1,2, \ldots$.

Substituting (14) and (15) into (A.8) yields

$$
m_{S, t}=m_{S, t-1}+\tau_{S, t}
$$

for $t=1,2,3, \ldots$ Set the following assumption:

Assumption $5 \tau_{S, t}=(\gamma-1) M_{t-1}$ for $t=1,2,3, \ldots$.

This assumption ensures (A.6) and

$$
m_{S, t}=M_{t}
$$

for $t=1,2,3, \ldots$, given $m_{S, 0}=M_{0}$ in an equilibrium. Given (A.6), a monetary steady state is defined as an equilibrium such that

$$
\frac{p_{A, t+1}}{p_{A, t}}=\frac{p_{M, t+1}}{p_{M, t}}=\frac{q_{t+1}}{q_{t}}=\frac{1}{\gamma} .
$$

The following assumption generalizes Assumption 3 for the case in which $\gamma \neq 1$.

Assumption 6 The function $f$ satisfies the following properties:

$$
\lim _{x \rightarrow 0} \frac{\gamma\left(x^{-1}-1\right)^{2}}{f^{\prime}(x)}>1
$$




$$
\frac{d}{d x}\left\{\gamma\left(\frac{1}{x}-1\right)^{2}\right\}<f^{\prime \prime}(x) \quad \text { for all } x \in\left(0, \frac{\gamma}{1+\gamma}\right)
$$

With money growth and Assumption 6, the following proposition holds in a monetary steady state:

Proposition 5 Suppose $M_{0}>0$ and that Assumptions 2, 5, and 6 hold. There exists a monetary steady state such that

$$
\begin{gathered}
x_{P, t}=x_{P}^{*} \equiv f^{\prime-1}\left(\frac{1}{\gamma}\right), \\
q_{t}=p_{A, t}=p_{M, t}=\left\{\begin{array}{ll}
\frac{1-x_{P}^{*}}{M_{t}} & \text { if } \frac{1}{\gamma}>\rho \\
\text { any real number in }\left[\frac{x_{P}^{*}}{\gamma M_{t}}, \frac{1-x_{P}^{*}}{M_{t}}\right] & \text { if } \frac{1}{\gamma}=\rho
\end{array},\right. \\
c_{S, Y, t}= \begin{cases}0 & \text { if } \frac{1}{\gamma}>\rho \\
1-x_{P}^{*}-p_{A, t} M_{t} & \text { if } \frac{1}{\gamma}=\rho,\end{cases}
\end{gathered}
$$

if $\rho \gamma \leq 1$ and $x_{P}^{*} \leq \gamma(1+\gamma)^{-1}$;

$$
\begin{gathered}
x_{P, t}=x_{P}^{* *} \text { such that } f^{\prime}\left(x_{P}^{* *}\right)=\gamma\left(\frac{1}{x_{P}^{* *}}-1\right)^{2}, \\
\left(q_{t}, p_{A, t}, p_{M, t}\right)=\left(\frac{x_{P}^{* *}}{\gamma M_{t}}, \gamma\left(\frac{1}{x_{P}^{* *}}-1\right) q_{t}, \gamma^{2}\left(\frac{1}{x_{P}^{* *}}-1\right)^{2} q_{t}\right), \\
c_{S, Y, t}=0
\end{gathered}
$$

where $x_{P}^{* *} \in\left(0, \gamma(1+\gamma)^{-1}\right)$, if $\rho \gamma \leq 1$ and $x_{P}^{*}>\gamma(1+\gamma)^{-1}$;

$$
\begin{gathered}
x_{P, t}=x_{P}^{* * *} \equiv f^{\prime-1}\left(\rho^{2} \gamma\right), \\
\left(q_{t}, p_{A, t}, p_{M, t}\right)=\left(\frac{x_{P}^{* * *}}{\gamma M_{t}}, \rho \gamma q_{t}, \rho^{2} \gamma^{2} q_{t}\right), \\
c_{S, Y, t}=1-x_{P}^{* * *}-p_{A, t} M_{t}
\end{gathered}
$$

if $\rho \gamma>1$ and $x_{P}^{* * *} \leq(1+\rho)^{-1}$; and $(A .17)-(A .19)$ hold where $x_{P}^{* *} \in\left(0,(1+\rho)^{-1}\right)$, if $\rho \gamma>1$ and $x_{P}^{* * *}>(1+\rho)^{-1}$. In all four cases, 


$$
b_{S, t}=b_{P, t}=m_{S, t+1}^{\prime}=\frac{x_{P, t}}{q_{t}},
$$

Proof Given $q_{t}>0$ in a monetary steady state, the two market clearing conditions, (14) and (15), and the first constraint in (12), i.e., $x_{P, t}=q_{t} b_{P, t}$, imply (A.23) immediately. Given $M_{0}>0$ and Assumption 5, $m_{S, t}=M_{t}=\gamma M_{t-1}$ for $t=1,2,3, \ldots$ Thus, (A.11) holds, as otherwise the value of $p_{A, t} m_{S, t}$ would not be constant. A constant value of $p_{A, t} m_{S, t}$ is necessary for $x_{P, t}$ and $c_{S, Y, t}$ being constant, because $p_{A, t} m_{S, t}=1-x_{P, t}-c_{S, Y, t}$, as implied by (A.23) and the first constraint in (A.7).

Given $q_{t}>0$ and the Inada condition satisfied by the function $f$, the first-order condition for $b_{P, t}$ in (12) implies

$$
f^{\prime}\left(q_{t} b_{P, t}\right)=\frac{p_{M, t+1}}{q_{t}}
$$

in a monetary steady state, which in turn implies $b_{P, t}>0$, as $p_{M, t+1}$ is finite in a monetary steady state.

Given $q_{t}>0$ and $b_{P, t}=b_{S, t}>0$ as implied by (15), the first-order conditions for $c_{S, Y, t}, b_{S, t}, m_{S, t}$, and $m_{S, t+1}^{\prime}$ in (A.7) are

$$
\begin{gathered}
-\eta_{1, t}+\rho+\underline{\lambda}_{c, S, t}=0, \\
-\eta_{1, t} q_{t}+p_{A, t+1}+\eta_{4, t}=0, \\
-\eta_{1, t} p_{A, t}+p_{A, t+1}+\bar{\lambda}_{m^{\prime}, S, t+1}+\underline{\lambda}_{m, S, t}=0, \\
p_{M, t+1}-p_{A, t+1}+\underline{\lambda}_{m^{\prime}, S, t+1}-\bar{\lambda}_{m^{\prime}, S, t+1}=0,
\end{gathered}
$$

respectively, where $\eta_{1, t}, \underline{\lambda}_{m^{\prime}, S, t+1}, \bar{\lambda}_{m^{\prime}, S, t+1}, \eta_{4, t}, \underline{\lambda}_{c, S, t}$, and $\underline{\lambda}_{m, S, t}$ are Lagrange multipliers for $c_{S, t}+q_{t} b_{S, t}+p_{A, t} m_{S, t}=1, \quad m_{S, t+1}^{\prime} \geq 0, \quad m_{S, t+1}^{\prime} \leq m_{S, t}+\tau_{S, t+1}, \quad b_{S, t} \geq 0$, $c_{S, Y, t} \geq 0$, and $m_{S, t} \geq 0$, respectively.

Because Assumption 5 implies $m_{S, t}=M_{t}=\gamma M_{t-1}$, it in turn implies that $m_{S, t}>0$, and thus $\underline{\lambda}_{m, S, t}=0$, given $M_{0}>0$. Also, (A.8) implies $m_{S, t}=b_{S, t}+m_{S, t}-m_{S, t+1}^{\prime}+\tau_{S, t+1}>0$, and (14) implies that $m_{S, t+1}^{\prime}>0$, given $b_{P, t}>0$. Hence, $\eta_{4, t}=0$ and $\underline{\lambda}_{m^{\prime}, S, t+1}=0$. Substituting these results into (A.25)(A.28) yields

$$
\begin{gathered}
\lambda_{c, S, t}=\eta_{1, t}-\rho \geq 0, \\
\eta_{1, t}=\frac{p_{A, t+1}}{q_{t}}=\frac{p_{M, t+1}}{p_{A, t}}, \\
\bar{\lambda}_{m^{\prime}, S, t+1}=p_{M, t+1}-p_{A, t+1} \geq 0 .
\end{gathered}
$$


Now split the parameter space into two regions: $\rho \leq \gamma^{-1}$ and $\rho>\gamma^{-1}$. Suppose $\rho \leq \gamma^{-1}$ and $p_{M, t+1}=p_{A, t+1}$. In this case,

$$
\eta_{1, t}=\frac{p_{M, t+1}}{p_{A, t}}=\frac{p_{A, t+1}}{p_{A, t}}=\frac{1}{\gamma}
$$

given (A.11). Thus,

$$
\begin{gathered}
\frac{p_{A, t}}{q_{t}}=\frac{p_{A, t+1}}{q_{t}} \cdot \frac{p_{A, t}}{p_{A, t+1}}=\eta_{1, t} \gamma=1, \\
f^{\prime}\left(q_{t} b_{P, t}\right)=\frac{p_{M, t+1}}{q_{t}}=\frac{p_{A, t+1}}{q_{t}}=\frac{1}{\gamma}
\end{gathered}
$$

as implied by (A.11) and (A.24). Because $f^{\prime \prime}<0$, the inverse function of $f^{\prime}, f^{\prime-1}$, exists. Therefore, the steady state value of $q_{t} b_{P, t}$ is unique. Given $\underline{\lambda}_{c, S, t} \geq 0$ and $\bar{\lambda}_{m^{\prime}, S, t+1}=0, c_{S, Y, t} \geq 0$ and $b_{P, t}=m_{S, t+1}^{\prime} \leq m_{S, t}+\tau_{S, t+1}$. These constraints are satisfied if and only if

$$
\begin{gathered}
q_{t} b_{P, t}=q_{t} m_{S, t+1}^{\prime} \leq q_{t}\left(m_{S, t}+\tau_{S, t+1}\right)=\gamma q_{t} m_{S, t} \\
c_{S, Y, t}=1-q_{t} b_{S, t}-p_{A, t} m_{S, t}=1-q_{t} b_{P, t}-q_{t} m_{S, t} \geq 0
\end{gathered}
$$

given Assumption 5 and (A.33). Denote $f^{\prime-1}\left(\gamma^{-1}\right)$ by $x_{P}^{*}$. These conditions are equivalent to

$$
q_{t} m_{S, t} \in\left[\frac{x_{P}^{*}}{\gamma}, 1-x_{P}^{*}\right] .
$$

This range is non-empty if and only if $x_{P}^{*} \leq \gamma(1+\gamma)^{-1}$. If $\rho=\gamma^{-1}$, then $\underline{\lambda}_{c, S, t} \geq 0=\eta_{1, t}-\rho=0$. Thus, $c_{S, Y, t}$ is indeterminate, and any value of $q_{t} m_{S, t}$ in this range can be a steady state value. If $\rho<\gamma^{-1}$, then $\eta_{1, t}>\rho$. Hence, $c_{S, Y, t}=0$, which implies $q_{t} m_{S, t}=q_{t} M_{t}=1-x_{P}^{*}$. The results described in this paragraph are sufficient for (A.14)-(A.16).

If $\quad \rho \leq \gamma^{-1} \quad$ and $\quad p_{M, t+1}>p_{A, t+1}, \quad$ then $\quad \bar{\lambda}_{m^{\prime}, S, t+1}>0 . \quad$ Thus, $b_{P, t}=m_{S, t+1}^{\prime}=m_{S, t}+\tau_{S, t+1}=\gamma m_{S, t}$, given Assumption 5. Also,

$$
\eta_{1, t}=\frac{p_{M, t+1}}{p_{A, t}}=\frac{p_{M, t+1}}{p_{A, t+1}} \frac{p_{A, t+1}}{p_{A, t}}>\frac{1}{\gamma} \geq \rho .
$$

Hence, $\underline{\lambda}_{c, S, t}>0$ and $c_{S, Y, t}=1-q_{t} b_{S, t}-p_{A, t} m_{S, t}=0$. Therefore,

$$
\eta_{1, t}=\frac{p_{A, t+1}}{q_{t}}=\frac{p_{A, t}}{q_{t}} \frac{p_{A, t+1}}{p_{A, t}}=\frac{1}{x_{P, t}}-1
$$

given $b_{P, t}=\gamma m_{S, t}$. As a result, (A.24) implies that 


$$
f^{\prime}\left(x_{P, t}\right)=\frac{p_{M, t+1}}{q_{t}}=\frac{p_{A, t+1}}{q_{t}} \cdot \frac{p_{A, t}}{p_{A, t+1}} \cdot \frac{p_{M, t+1}}{p_{A, t}}=\left(\frac{p_{A, t+1}}{q_{t}}\right)^{2} \frac{p_{A, t}}{p_{A, t+1}}=\gamma\left(\frac{1}{x_{P, t}}-1\right)^{2}
$$

given (A.11), (A.30), and (A.39). As implied by (A.38) and (A.39), the solution for this equation must satisfy $\frac{1}{x_{P, t}}-1>\frac{1}{\gamma}$, or $x_{P, t}<\gamma(1+\gamma)^{-1}$. Given Assumption 6, $f^{\prime}\left(x_{P, t}\right)$ and $\gamma\left(x_{P, t}^{-1}-1\right)^{2}$ can have only one intersection for $x_{P, t} \in\left(0, \gamma(1+\gamma)^{-1}\right)$ at most, and they do have one if and only if $f^{\prime}\left(\gamma(1+\gamma)^{-1}\right)>\gamma\left[\gamma^{-1}(1+\gamma)-1\right]^{2}=\gamma^{-1}$, or $x_{P}^{*} \equiv f^{\prime-1}\left(\gamma^{-1}\right)>\gamma(1+\gamma)^{-1}$. Given $m_{S, t}=M_{t}$ and (A.11), the results described in this paragraph are sufficient for (A.17)-(A.19).

Suppose $\rho>\gamma^{-1}$. Because $\eta_{1, t}=p_{M, t+1} p_{A, t+1}^{-1} \gamma^{-1}$ as implied by (A.30), (A.29) requires $p_{M, t+1} \geq \rho \gamma p_{A, t+1}$. Thus, $\bar{\lambda}_{m^{\prime}, S, t+1}>0$ and $m_{S, t+1}^{\prime}=m_{S, t}+\tau_{S, t+1}$, given $\rho>\gamma^{-1}$ and (A.31). Hence,

$$
b_{P, t}=b_{S, t}=\gamma m_{S, t}
$$

given (14), (15), and Assumption 5 in this case.

If $\rho>\gamma^{-1}$ and $p_{M, t+1}=\rho \gamma p_{A, t+1}$, then $\eta_{1, t}=p_{M, t+1} p_{A, t}^{-1}=\rho>\gamma^{-1}$, given (A.11) and (A.30). Thus, $\underline{\lambda}_{c, S, t}=0$ and $c_{S, Y, t}=1-q_{t} b_{S, t}-p_{A, t} m_{S, t} \geq 0$, as implied by (A.29). In this case, (A.24) implies that

$$
f^{\prime}\left(x_{P, t}\right)=\frac{p_{M, t+1}}{q_{t}}=\frac{p_{A, t+1}}{q_{t}} \cdot \frac{p_{A, t}}{p_{A, t+1}} \cdot \frac{p_{M, t+1}}{p_{A, t}}=\rho^{2} \gamma
$$

given (A.11) and (A.30). Because $\eta_{1, t}=p_{A, t+1} q_{t}^{-1}=\rho$ and (A.30) also imply that $p_{A, t}=\rho \gamma q_{t}, c_{S, Y, t}=1-q_{t} b_{S, t}-p_{A, t} m_{S, t} \geq 0$ implies that $x_{P, t} \leq 1-\rho \gamma q_{t} m_{S, t}$, given the first constraint in (12). Also, $x_{P, t}=q_{t} b_{P, t}=\gamma q_{t} m_{S, t}$ as implied by (A.41). Thus, the unique root for $x_{P, t}$ in (A.42) must be in $\left(0,(1+\rho)^{-1}\right)$. The results described in this paragraph are sufficient for (A.20)-(A.22).

If $\rho>\gamma^{-1} \quad$ and $\quad p_{M, t+1}>\rho \gamma p_{A, t+1}$, then $\quad \underline{\lambda}_{c, S, t}>0 \quad$ and $c_{S, Y, t}=1-q_{t} b_{S, t}-p_{A, t} m_{S, t}=0$. Thus, (A.39) holds, given $\bar{b}_{P, t}^{c, S, t}=b_{S, t}=\gamma m_{S, t}$. Hence, (A.40) holds. Also, $\eta_{1, t}=p_{M, t+1} p_{A, t+1}^{-1} \gamma^{-1}>\rho$ and (A.39) imply that (A.40) must have a root for $x_{P, t}$ in $\left(0,(1+\rho)^{-1}\right)$ if there exists a monetary steady state in this case. Because $\rho>\gamma^{-1}$ implies that $(1+\rho)^{-1}<\gamma(1+\gamma)^{-1}$, Assumption 6 implies that $f^{\prime}\left(x_{P, t}\right)$ and $\gamma\left(x_{P, t}^{-1}-1\right)^{2}$ can have only one intersection for $x_{P, t} \in\left(0,(1+\rho)^{-1}\right)$ at most, and that they do have one if and only if $f^{\prime}\left((1+\rho)^{-1}\right)>\gamma[(1+\rho)-1]^{2}=\rho^{2} \gamma$. The results described in this paragraph are sufficient for (A.17)-(A.19).

\section{Appendix C: Proof of Proposition 4}

Given $q_{t}>0$ in a monetary steady state, the first-order conditions for $c_{S, t}, m_{S, t}, m_{S, t+1}^{\prime}$, $b_{S, t}$, and $x_{P, t}$ in (11) with (35) and (12) imply that

$$
\rho-\eta_{t}+\underline{\phi}_{c, t}=0
$$




$$
\begin{gathered}
-\eta_{t} p_{A, t}+p_{A, t+1}+\lambda_{t+1}+\underline{\phi}_{m, t}=0, \\
p_{M, t+1}-p_{A, t+1}-\lambda_{t+1}=0, \\
-\eta_{t} q_{t}+p_{A, t+1}+\lambda_{t+1}=0, \\
f^{\prime}\left(x_{P, t}\right)=\frac{p_{M, t+1}}{q_{t}}
\end{gathered}
$$

respectively, where $\eta_{t}, \lambda_{t+1}, \underline{\phi}_{m, t}$, and $\underline{\phi}_{c, t}$ are Lagrange multipliers for $c_{S, t}+q_{t} b_{S, t}+p_{A, t} m_{S, t}=1, m_{S, t+1}^{\prime} \leq m_{S, t}+b_{S, t}, m_{S, t} \geq 0$, and $c_{S, t} \geq 0$. As old suppliers can borrow fiat money from the central bank to pay for goods in the morning goods market, old producers can repay their nominal debt even if old suppliers do not hold any fiat money at the beginning of each period. Thus, $m_{S, t} \geq 0$ can bind in a monetary steady state. The non-negativity constraints on $m_{S, t+1}^{\prime}, b_{S, t}$, and $c_{S, O, t+1}$ in (11) do not bind for the same reason as described in the proof of Proposition 2.

These equations imply $\lambda_{t+1}>0$ or $\underline{\phi}_{m, t}>0$ in a monetary steady state, because if $\lambda_{t+1}=\underline{\phi}_{m, t}=0$, then $\eta_{t} p_{A, t}=p_{A, t+1} \geq \rho p_{A, t}$, which cannot hold, given $p_{A, t}=p_{A, t+1}>0$ for all $t$ in a monetary steady state and (4).

If $\lambda_{t+1}>0$, then old suppliers have no fiat money to pay to young suppliers in the afternoon goods market, because $b_{S, t}+m_{S, t}-m_{S, t+1}^{\prime}=0$. Thus, $m_{S, t+1}=0$ in this case. If $\underline{\phi}_{m, t}>0$, then $m_{S, t}=0$. Thus, $m_{S, t}=0$ in any case, given $m_{S, t}=m_{S, t+1}$ in a monetary steady state. Therefore, the fixed supply of fiat money, $M$, must be set to zero to allow the existence of a monetary steady state, as implied by (13). Given $m_{S, t}=M=0$ and (13), $m_{S, t+1}^{\prime}=b_{S, t}$ in a monetary steady state. Hence, (38) holds in a monetary steady state, as implied by (15).

Given $m_{S, t}=0$, (15) and the first constraints in (11) and (12) jointly imply that $c_{S, t}=1-q_{t} b_{S, t}=1-x_{P, t}$. Because (A.45)-(A.47) imply $\eta_{t}=p_{M, t+1} / q_{t}=f^{\prime}\left(x_{P, t}\right)$, $x_{P, t} \leq x^{*}$ in a monetary steady state, given $\eta_{t} \geq \rho$ as implied by (A.43). Thus, $c_{S, t}>0$, and hence $\underline{\phi}_{c, t}=0$, in a monetary steady state, given (2) and the strict concavity of the function $f$.

Given $\underline{\phi}_{c, t}=0$, (A.43) implies $\eta_{t}=\rho$. Thus, combining (A.45)-(A.47) yields $f^{\prime}\left(x_{P, t}\right)=p_{M, t+1} / q_{t}=\rho$, i.e., (36) and (37), which in turn implies $q_{t} b_{P, t}=x^{*}$, as implied by the first constraint in (12).

In addition, (A.45) and (A.46) imply that $p_{M, t+1} \geq p_{A, t+1}$ and $\rho q_{t} \geq p_{A, t+1}$, given $\lambda_{t+1} \geq 0$. Combining (A.44) and (A.46) yields $p_{A, t} \geq q_{t}$, given $\underline{\phi}_{m, t} \geq 0$ and $\eta_{t}=\rho>0$. Thus, the values of $q_{t}$ and $p_{A, t}$ are indeterminate in the monetary steady state, as long as they satisfy $q_{t}>0$ and $p_{A, t} \in\left[q_{t}, \rho q_{t}\right]$. 


\section{References}

Afonso, G., \& Shin, H. S. (2011). Precautionary demand and liquidity in payment systems. Journal of Money, Credit and Banking, 43(7), 589-619.

Antinolfi, G., \& Keister, T. (2006). Discount window policy, banking crises, and indeterminacy of equilibrium. Macroeconomic Dynamics, 10(01), 1-19.

Chapman, J. T. E., \& Martin, A. (2013). Rediscounting under aggregate risk with moral hazard. Journal of Money, Credit, and Banking, 45(4), 651-674.

Doepke, M., \& Schneider, M. (2017). Money as a unit of aaccount. Econometrica, 85(5), 1537-74.

Freeman, S. (1996a). The payments system, liquidity, and rediscounting. American Economic Review, $86(5), 1126-1138$.

Freeman, S. (1996b). Clearinghouse banks and banknote over-issue. Journal of Monetary Economics, 38(1), 101-115.

Freeman, S. (1999). Rediscounting under aggregate risk. Journal of Monetary Economics, 43(1), $197-216$.

Fujiki, H. (2003). A model of the Federal Reserve Act under the international gold standard system. Journal of Monetary Economics, 50(6), 1333-1350.

Fujiki, H. (2006). Institutions of foreign exchange settlement in a two-country model. Journal of Money, Credit and Banking, 38(3), 697-719.

Green, E. J. (1997). Money and debt in the structure of payments. Monetary and Economic Studies, Bank of Japan, 15(1), 63-87.

Gorton, G. (1999). Pricing free bank notes. Journal of Monetary Economics, 44(1), 33-64.

Gu, C., Guzman, M., \& Haslag, J. (2011). Production, hidden action, and the payment system. Journal of Monetary Economics, 58(2), 172-182.

Hancock, D., \& Wilcox, J. A. (1996). Intraday management of bank reserves: The effects of caps and fees on daylight overdrafts. Journal of Money, Credit and Banking, 28(4), 870-908.

Hart, O., \& Moore, J. (1994). A theory of debt based on the inalienability of human capital. Quarterly Journal of Economics, 109(4), 841-879.

Hart, O., \& Moore, J. (1998). Default and renegotiation: A dynamic model of debt. Quarterly Journal of Economics, 113(1), 1-41.

Jovanic, B., \& Ueda, M. (1997). Contracts and money. Journal of Political Economy, 105(4), 700-708.

Kiyotaki, N., \& Moore, J. (1997). Credit cycles. Journal of Political Economy, 105(2), 211-248.

Kiyotaki, N., \& Moore, J. (2005). Financial deepening. Journal of the European Economic Association, 3(2-3), 701-713.

Kiyotaki, N., \& Wright, R. (1989). On money as a medium of exchange. Journal of Political Economy, 97(4), 927-954.

Lagos, R., \& Wright, R. (2005). A unified framework for monetary theory and policy analysis. Journal of Political Economy, 113(3), 463-484.

Martin, A. (2004). Optimal pricing of intraday liquidity. Journal of Monetary Economics, 51(2), $401-424$.

Mills, D. C, Jr. (2006). Alternative central bank credit policies for liquidity provision in a model of payments. Journal of Monetary Economics, 53(7), 1593-1611.

Samuelson, P. A. (1958). An exact consumption loan model of interest, with or without the social contrivance of money. Journal of Political Economy, 66(5), 467-482.

Sargent, T., \& Wallace, N. (1982). The real-Bills doctrine versus the quantity theory: A reconsideration. Journal of Political Economy, 90(6), 1212-36.

Smith, B. D. (2002). Monetary policy, banking crises, and the friedman rule. American Economic Review, 92(2), 128-134.

Tabellini, G., \& Freeman, S. (1998). The optimality of nominal contracts. Economic Theory, 11(3), $545-562$.

Tomura, H. (2020). "Nominal Contracts and the Payment System," WINPEC Working Paper E-, Waseda University.

Townsend, R.M. (1980). Models of Money with Spatially Separated Agents. In J. Kareken, N. Wallace (Ed.) Models of Monetary Economies, (pp. 265-303). Federal Reserve Bank of Minneapolis.

Williamson, S., \& Wright, R. (1994). Barter and monetary exchange under private information. American Economic Review, 84(1), 104-123. 
Zhou, R. (2000). Understanding Intraday Credit in Large-Value Payment Systems. Economic Perspectives, Federal Reserve Bank of Chicago, vol. 25(Q III), (pp. 29-44).

Publisher's Note Springer Nature remains neutral with regard to jurisdictional claims in published maps and institutional affiliations. 